\title{
Effects of concomitant use of prasugrel with edoxaban on bleeding time, pharmacodynamics, and pharmacokinetics of edoxaban in healthy elderly Japanese male subjects: a clinical pharmacology study
}

Ippei Ikushima1*, Takaaki Akasaka², Yoshiyuki Morishima², Atsushi Takita ${ }^{3}$, Tomoko Motohashi ${ }^{2}$ and Tetsuya Kimura ${ }^{2}$

\begin{abstract}
Background: Dual therapy with a direct oral anticoagulant (DOAC) plus a $\mathrm{P}_{2} \mathrm{Y}_{12}$ receptor inhibitor is recommended in patients with nonvalvular atrial fibrillation who undergo percutaneous coronary intervention. Thus, we evaluated the effects of DOAC edoxaban plus $\mathrm{P}_{2 \mathrm{Y}_{12}}$ receptor inhibitor prasugrel on bleeding time (BT), and pharmacodynamics (PD) and pharmacokinetics (PK) of edoxaban in healthy elderly Japanese male subjects.

Methods: A single-center, clinical pharmacology study with randomized, open-label, repeated dosing enrolled 24 participants in two groups of 12 receiving $30 \mathrm{mg}$ edoxaban once daily for 3 days; then $30 \mathrm{mg}$ edoxaban plus $2.5 \mathrm{mg}$ prasugrel (Group 1) or $30 \mathrm{mg}$ edoxaban plus $3.75 \mathrm{mg}$ prasugrel (Group 2) once daily for 5 days. Primary endpoint was BT by the Ivy method. Secondary endpoints were the PD parameters of prothrombin time (PT), activated partial thromboplastin time (aPTT), prothrombin fragment $\mathrm{F} 1+2(\mathrm{~F} 1+2)$, and $\mathrm{P}_{2} \mathrm{Y}_{12}$ reaction units $(\mathrm{PRU})$, and PK profiles of edoxaban alone and in combination with prasugrel.

Results: Geometric least squares mean of BT ratios (vs. baseline) for 3-day edoxaban treatment were 1.097 (90\% confidence interval (Cl) 0.911-1.321) in Group 1 and 1.327 (90\% Cl 1.035-1.703) in Group 2; for 5-day edoxaban plus $2.5 \mathrm{mg}$ and $3.75 \mathrm{mg}$ prasugrel, they were 1.581 ( $90 \% \mathrm{Cl} 1.197-2.087)$ and 1.996 (90\% Cl 1.482-2.690), respectively. Contributions of prasugrel to the effects (edoxaban + prasugrel/edoxaban) were 1.442 (90\% Cl 1.096-1.897) in Group 1 and 1.504 (90\% Cl 1.172-1.930) in Group 2. Edoxaban prolonged PT and aPTT and decreased F1 + 2. Adding on prasugrel did not appreciably change PT, aPTT, or F1 + 2. Prasugrel reduced PRU, whereas edoxaban had no effect on PRU. We recorded 26 adverse events; 23 were treatment-emergent (positive fecal occult blood test). All participants with adverse events recovered during follow-up.

(Continued on next page)
\end{abstract}

\footnotetext{
* Correspondence: ippei-ikushima@lta-med.com

${ }^{1}$ Sumida Hospital, 29-1, Honjo 1-Chome, Sumida-ku, Tokyo 130-0004, Japan

Full list of author information is available at the end of the article
} 
(Continued from previous page)

Conclusions: Coadministration of $2.5 \mathrm{mg}$ and $3.75 \mathrm{mg}$ prasugrel with $30 \mathrm{mg}$ edoxaban prolonged BT in healthy elderly Japanese male subjects. The effect was dependent on the dose of prasugrel. Prasugrel did not affect PD or PK profiles of edoxaban. Edoxaban had no effect on PD of prasugrel.

Trial registration: Japan Registry of Clinical Trials No. jRCTs071190006; registration date, 26-April-2019.

Keywords: Edoxaban, Prasugrel, Healthy male subjects, Elderly Japanese, Bleeding time, Pharmacodynamics, Pharmacokinetics

\section{Background}

In patients with nonvalvular atrial fibrillation (NVAF), especially in those of advanced aged, coronary artery disease is common. In the All Nippon AF in the Elderly (ANAFIE) registry of 32,726 Japanese patients $\geq 75$ years of age, $5600(17.1 \%)$ had angina pectoris and 1874 (5.7\%), a myocardial infarction [1].

The European Heart Rhythm Association, a branch of the European Society of Cardiology issued a 2018 joint European consensus document on the management of antithrombotic therapy in atrial fibrillation (AF) patients presenting with acute coronary syndrome and undergoing percutaneous coronary intervention (PCI) [2]. The document recommends as short a period as possible for triple therapy with an oral anticoagulant plus dual antiplatelet agents (a $\mathrm{P}_{2} \mathrm{Y}_{12}$ receptor inhibitor and aspirin), followed by dual therapy with an oral anticoagulant plus a single antiplatelet agent ( $\mathrm{P} 2 \mathrm{Y}_{12}$ receptor inhibitor).

The direct oral anticoagulant (DOAC) used in our study was edoxaban, a direct inhibitor of activated blood coagulation factor $\mathrm{X}$, indicated to reduce the risk of stroke and systemic embolism in patients with NVAF [3, 4]. Edoxaban is available in a standard dose of $60 \mathrm{mg}$ and a reduced dose of $30 \mathrm{mg}$ for patients with low body weight $(\leq 60 \mathrm{~kg})$, moderate or severe renal impairment (creatinine clearance $15-50 \mathrm{~mL} / \mathrm{min})$, or concomitant use of potent Pglycoprotein inhibitors $[4,5]$. According to baseline clinical characteristics of patients taking edoxaban enrolled in the ANAFIE registry (all 75 years of age or older), $82.2 \%$ of them were taking this reduced $30 \mathrm{mg}$ dose [1].

The $\mathrm{P}_{2} \mathrm{Y}_{12}$ receptor inhibitor administered with edoxaban in this study was prasugrel, indicated for patients with acute coronary syndrome, stable angina, or old myocardial infarction who are to be managed with PCI in Japan [6, 7]. Compared to clopidogrel, prasugrel is a more potent $\mathrm{P}_{2} \mathrm{Y}_{12}$ receptor inhibitor [6-9]. In Japan, the doses of prasugrel (loading dose, $20 \mathrm{mg}$; standard daily maintenance dose, $3.75 \mathrm{mg}$; reduced daily maintenance dose, $2.5 \mathrm{mg}$ for patients with low body weight $\leq 50$ $\mathrm{kg}$ ) are lower than those approved in western countries (loading dose, $60 \mathrm{mg}$; daily maintenance dose, $10 \mathrm{mg}$ ), and the bleeding risk of prasugrel was shown to be similar to that of clopidogrel $[8,9]$. Recently, a retrospective analysis of an observational cohort study reported that in Japanese AF patients undergoing PCI, prasugrel as a part of triple therapy with aspirin and an oral anticoagulant had not increased the risk of bleeding compared to clopidogrel [10]. Besides this observational study, a phase $3 \mathrm{~b}$ trial [11] was conducted to analyze the safety of edoxaban in combination with a $\mathrm{P}_{2} \mathrm{Y}_{12}$ receptor inhibitor in AF patients undergoing PCI. The study demonstrated that edoxaban plus a $\mathrm{P}_{2} \mathrm{Y}_{12}$ receptor inhibitor was non-inferior for bleeding events compared with a vitamin $\mathrm{K}$ antagonist in combination with a $\mathrm{P}_{2} \mathrm{Y}_{12}$ receptor inhibitor and aspirin without significant differences in ischemic events. However, data on the combination of edoxaban and prasugrel are very limited.

Here, we aimed to assess the effects of edoxaban plus prasugrel on bleeding time (BT), and pharmacodynamic (PD) and pharmacokinetic (PK) profiles of edoxaban in healthy elderly Japanese male subjects between the ages of 65 and 80 .

\section{Methods \\ Study population}

The target sample size for the study population was 24 healthy elderly Japanese male subjects between the ages of 65 and 80 years, weighing $40 \mathrm{~kg}-60 \mathrm{~kg}$ (body mass index [BMI], $18.5 \mathrm{~kg} / \mathrm{m}^{2}-25.0 \mathrm{~kg} / \mathrm{m}^{2}$ ). Subjects were excluded from participation in the study for any of the following reasons: presence of a bleeding disorder (history of intracranial bleeding, gastrointestinal bleeding, vitreous hemorrhage, retinal bleeding, hemoptysis, hematemesis, hematuria, bloody stools, hemorrhoids), prolonged BT of over $9.5 \mathrm{~min}$, and prolonged prothrombin time (PT) and activated partial thromboplastin time (aPTT) exceeding the upper limit of normal values, a positive finding in fecal occult blood test or urine occult blood test, chronic kidney disease (estimated glomerular filtration rate (eGFR) of less than $60 \mathrm{~mL} / \mathrm{min} / 1.73 \mathrm{~m}^{2}$ ), or use or consumption any of the following within 7 days before the examination: inhibitors or inducers of the drug-metabolizing enzyme CYP3A, inhibitors of P-glycoprotein, and grapefruit or any food products containing the fruit.

\section{Study design}

This study was a randomized, open-label, parallel-group, repeated-dose study conducted at a single center. 
Subjects who were eligible and agreed to participate in this study were admitted to the hospital for the length of the study and randomly assigned to two groups: Group $1,30 \mathrm{mg}$ edoxaban (dose for NVAF patients weighing $60 \mathrm{~kg}$ or less) plus $2.5 \mathrm{mg}$ prasugrel (reduced maintenance dose in Japan); Group 2, $30 \mathrm{mg}$ edoxaban plus 3.75 mg prasugrel (standard maintenance dose in Japan).

The study design, schedule of procedures, and blood sample collections are summarized in Table 1. This study was conducted at Sumida Hospital in Tokyo, Japan, from May to June 2019.

\section{Bleeding time}

We measured BT by the Ivy method [12] using a needle type of BD Microtainer Contact-Activated Lancet device (Becton, Dickinson and Company, USA). The incision was made in the lateral aspect of the forearm by puncturing at one arbitrary site with the device. After the incision, we blotted the blood every $30 \mathrm{~s}$ with filter paper until the bleeding reached hemostasis and recorded the time from the puncture to the end of bleeding. When the time to hemostasis exceeded $10 \mathrm{~min}$, it was recorded as such, ending the observation. The schedule of BT evaluations is included in Table 1. Baseline BT was measured on the day of admission at approximately the same time of day as the BT evaluations on Day 3 and Day 8, 3 hours after the administration of study drug(s).

\section{Pharmacodynamics}

Effects of edoxaban alone and edoxaban plus prasugrel on the parameters of blood coagulation and platelet aggregation were assessed by determination of PT, aPTT, prothrombin fragment $1+2(\mathrm{~F} 1+2)$, and $\mathrm{P}_{2} \mathrm{Y}_{12}$ reaction units (PRU). Blood was collected in a vacuum blood collection tube containing $3.2 \%$ sodium citrate, and the schedule for the blood sample collection is shown in Table 1. Blood coagulation marker PT was measured by PT reagent Thrombocheck-PT in system CS-200i (Sysmex Corporation, Japan); aPTT by aPTT reagent HemosIL SynthASil in system ACL TOP Base (IL, Japan; Instrumentation Laboratory, USA) and $\mathrm{F} 1+2$ by ELISA Enzygnost F1 +2 monoclonal reagent in system Behring ELISA Processor III and DiaSorin (BIT Analytical Instruments $\mathrm{GmbH}$, Germany). These assays were carried out at LSI Medience Corporation (Tokyo, Japan). We measured PRU with VerifyNow system (Instrumentation Laboratory, Bedford, MA, USA) at Sumida Hospital.

\section{Pharmacokinetics}

Blood for the determination of plasma edoxaban concentrations was collected from a forearm vein and deposited in a vacuum blood collection tube containing heparin sodium. Blood was collected before the administration and $0.25,0.5,1,2,3,4,8,12$, and $24 \mathrm{~h}$ after the drug administration on Day 1, Day 3, and Day 8 (Table 1). Plasma samples were obtained by centrifugation, and the samples were immediately frozen at $-20^{\circ} \mathrm{C}$ or lower. Plasma edoxaban concentrations were measured by a liquid chromatography-tandem mass spectrometry system (SCIEX, Framingham, MA, USA) at Shin Nippon Biomedical Laboratories, Ltd. (Wakayama, Japan).

\section{Statistical analysis}

The sample size selected was 24 (12 in each group) based on feasibility. According to results of phase 1 studies of edoxaban and prasugrel, inter-individual variations in BT and $\mathrm{BT}$ ratio before and after the administration were 20 to $45 \%$, and intra-individual variations were estimated to be 20 to $30 \%$. Under this estimation, effects of drugs on bleeding time could be analyzed with a certain degree of

Table 1 Study design, schedule for BT, PD, and edoxaban PK evaluations

\begin{tabular}{|c|c|c|}
\hline Subjects & \multicolumn{2}{|l|}{ Healthy elderly Japanese male subjects (Age: 65-80) } \\
\hline Study design & \multicolumn{2}{|l|}{ Open-label, parallel-group, repeated-dose } \\
\hline \multirow[t]{2}{*}{ Sample size } & \multicolumn{2}{|l|}{24 Subjects randomized into two groups } \\
\hline & $\begin{array}{l}\text { Group } 1, n=12 \\
30 \mathrm{mg} \text { Edoxaban }+2.5 \mathrm{mg} \text { Prasugrel }\end{array}$ & $\begin{array}{l}\text { Group } 2, n=12 \\
30 \text { mg Edoxaban }+3.75 \text { mg Prasugrel }\end{array}$ \\
\hline \multirow[t]{2}{*}{ Treatments } & \multicolumn{2}{|l|}{ Stage 1: all participants Day 1, 2, 3: $30 \mathrm{mg}$ Edoxaban once daily } \\
\hline & $\begin{array}{l}\text { Stage 2: Day 4, 5, 6, 7, } 8 \\
\text { Group 1: } 30 \mathrm{mg} \text { Edoxaban }+2.5 \mathrm{mg} \text { Prasugrel once daily }\end{array}$ & $\begin{array}{l}\text { Stage 2: Day 4, 5, 6, 7, } 8 \\
\text { Group 2: } 30 \text { mg Edoxaban }+3.75 \mathrm{mg} \\
\text { Prasugrel once daily }\end{array}$ \\
\hline \multicolumn{3}{|c|}{ Schedule of procedures and blood sample collections } \\
\hline Bleeding time $(\mathrm{BT})^{\mathrm{a}} \&$ PD Evaluation ${ }^{\mathrm{b}}$ & \multicolumn{2}{|c|}{$\begin{array}{l}\text { Day 0: Day of admission } \\
\text { Day 3: Three hours after administration of edoxaban } \\
\text { Day 8: Three hours after administration of edoxaban }+ \text { prasugrel }\end{array}$} \\
\hline Edoxaban PK & \multicolumn{2}{|c|}{$\begin{array}{l}\text { Day 1: Pre-administration of study drug } \\
\text { Day 3: Pre-administration and } 0.25,0.5,1,2,3,4,8,12,24 \mathrm{~h} \text { after administration of edoxaban } \\
\text { Day 8: Pre-administration and } 0.25,0.5,1,2,3,4,8,12,24 \mathrm{~h} \text { after administration of edoxaban + prasugre }\end{array}$} \\
\hline
\end{tabular}

avy Method

${ }^{\mathrm{b}} \mathrm{PD}$ indices: prothrombin time (PT), activated partial thromboplastin time (aPTT), prothrombin fragment $1+2(\mathrm{~F} 1+2)$, and $\mathrm{P} 2 \mathrm{Y}_{12}$ reaction units $(\mathrm{PRU})$ 
accuracy. All statistical analyses were performed using SAS Ver. 9.4 (SAS Institute Inc., Cary, NC, USA).

Summary statistics were calculated for baseline and postdose values for the primary endpoint of $\mathrm{BT}$ and secondary endpoints of PD indices (PT, aPTT, F1 + 2, PRU) for each target population. Furthermore, we calculated summary statistics of plasma edoxaban concentrations and estimated pharmacokinetic parameters $\left(C_{\text {max,ss }}\right.$, steady state maximum plasma concentration; $\mathrm{AUC}_{\mathrm{tau}, \mathrm{ss}}$, steady state area under the plasma concentration-time curve; $t_{\text {max,ss }}$, steady state time to reach maximum plasma concentration) using a noncompartmental analysis engine of Phoenix WinNonlin Ver. 8.1 based on Model 1200 (Extravascular). AUC tau,ss $_{\text {s }}$ was calculated by the linear-Log trapezoidal method.

For the primary endpoint analysis, a logarithmically converted value of BT for each sample was the dependent variable in a linear mixed model with fixed and random effects. We calculated geometric least squares means (GLSM) of ratios of BT for the edoxaban alone and the edoxaban plus prasugrel combination, with $90 \%$ confidence intervals (CIs) for each treatment group.

For the secondary endpoints analysis, we used the logarithmically converted $\mathrm{PK}$ parameters $\left(\mathrm{C}_{\mathrm{max}, \mathrm{ss}}, \mathrm{AUC}_{\mathrm{tau}, \mathrm{ss} \text {, }}\right.$ $\left.t_{\text {max,ss }}\right)$ as dependent variables in a linear mixed model with fixed and variable effects. We calculated GLSM of these values for edoxaban administered alone and edoxaban plus prasugrel combination, with $90 \%$ CIs.

\section{Results}

\section{Subject disposition and characteristics}

A total of 24 healthy Japanese male subjects (age range 6678 years) participated in this study: 12 administered $30 \mathrm{mg}$ edoxaban plus $2.5 \mathrm{mg}$ prasugrel (Group 1) and 12 administered $30 \mathrm{mg}$ edoxaban plus $3.75 \mathrm{mg}$ prasugrel (Group 2). All participants completed the study as planned. Demographic and clinical characteristics of participants are shown in Table 2.

All participant data was available for the final analyses.

\section{Bleeding time}

Mean and median BTs (min) at baseline and after treatments are shown in Table 3.

The increase in BT is expressed as a GLSM of BT ratios (expressed as ratios to baseline) are shown in a box plot (Fig. 1). After 3 days of a once-daily dosing of $30 \mathrm{mg}$ edoxaban, the GLSMs of BT ratios were 1.097 (90\% CI

Table 2 Baseline demographic and clinical characteristics

\begin{tabular}{|c|c|c|c|}
\hline & All subjects & $\begin{array}{l}\text { Group } 1 \\
30 \mathrm{mg} \text { edoxaban plus } \\
2.5 \mathrm{mg} \text { prasugrel }\end{array}$ & $\begin{array}{l}\text { Group } 2 \\
30 \mathrm{mg} \text { edoxaban plus } \\
3.75 \mathrm{mg} \text { prasugrel }\end{array}$ \\
\hline & $n=24$ & $n=12$ & $n=12$ \\
\hline \multicolumn{4}{|l|}{ Age (years) } \\
\hline Mean (SD) & $72(4)$ & $71(4)$ & $73(3)$ \\
\hline 65 to $<75, \mathrm{n}(\%)$ & $16(66.7)$ & $9(75.0)$ & $7(58.3)$ \\
\hline 75 to $80, \mathrm{n}(\%)$ & $8(33.3)$ & $3(25.0)$ & $5(41.7)$ \\
\hline \multicolumn{4}{|l|}{ Height $(\mathrm{cm})$} \\
\hline Mean (SD) & $164.0(5.7)$ & $162.5(5.7)$ & $165.5(5.6)$ \\
\hline \multicolumn{4}{|l|}{ Weight (kg) } \\
\hline Mean (SD) & $56.4(2.2)$ & $55.8(2.4)$ & $57.0(1.9)$ \\
\hline$>50$ to $60, \mathrm{n}(\%)$ & $24(100.0)$ & $12(100.0)$ & $12(100.0)$ \\
\hline \multicolumn{4}{|l|}{ BMI $\left(\mathrm{kg} / \mathrm{m}^{2}\right)$} \\
\hline Mean (SD) & $21.1(1.6)$ & $21.3(1.6)$ & $21.0(1.6)$ \\
\hline \multicolumn{4}{|c|}{ eGFR $\left(\mathrm{mL} / \mathrm{min} / 1.73 \mathrm{~m}^{2}\right)$} \\
\hline Mean (SD) & $73.5(7.0)$ & $75.5(6.6)$ & $71.6(7.1)$ \\
\hline 60 to < $90, \mathrm{n}(\%)$ & $24(100.0)$ & $12(100.0)$ & $12(100.0)$ \\
\hline \multicolumn{4}{|l|}{$\mathrm{CL}_{\mathrm{cr}}(\mathrm{mL} / \mathrm{min})$} \\
\hline Mean (SD) & $67.2(7.2)$ & $68.7(6.1)$ & $65.8(8.1)$ \\
\hline$\geq 50, \mathrm{n}(\%)$ & $24(100.0)$ & $12(100.0)$ & $12(100.0)$ \\
\hline \multicolumn{4}{|l|}{ Medical history ${ }^{\mathrm{a}}$} \\
\hline No, n (\%) & $10(41.7)$ & $5(41.7)$ & $5(41.7)$ \\
\hline Yes, n (\%) & $14(58.3)$ & $7(58.3)$ & $7(58.3)$ \\
\hline
\end{tabular}

$S D$ standard deviation, $I Q R$ interquartile range, $B M I$ body mass index, $C L_{c r}$ creatinine clearance

${ }^{a}$ Appendicitis, polyps in the colon, hemorrhoids, cataract, hepatitis $A$, tuberculosis, and inguinal hernia 
Table 3 Mean and median bleeding times (min)

\begin{tabular}{lll}
\hline & $\begin{array}{l}\text { Group 1 } \\
30 \mathrm{mg} \text { edoxaban plus } \\
2.5 \mathrm{mg} \text { prasugrel } \\
n=12\end{array}$ & $\begin{array}{l}\text { Group 2 } \\
30 \mathrm{mg} \text { edoxaban plus } \\
3.75 \mathrm{mg} \text { prasugrel } \\
n=12\end{array}$ \\
\hline Baseline & & \\
Mean (SD) & $3.2(0.8)$ & $3.5(1.1)$ \\
Median (IQR) & $3.0(2.5-3.8)$ & $3.5(2.5-4.5)$ \\
Edoxaban administration & \\
Mean (SD) & $3.5(0.6)$ & $4.7(1.6)$ \\
Median (IQR) & $3.5(3.0-4.0)$ & $4.5(3.3-6.0)$ \\
Edoxaban plus prasugrel administration & \\
Mean (SD) & $5.4(2.3)$ & $7.3(2.8)$ \\
Median (IQR) & $5.0(3.5-7.3)$ & $7.5(5.5-10.0)$ \\
\hline SD standard deviation, & IQR interquartile range
\end{tabular}

0.911-1.321) in Group 1 and 1.327 (90\% CI 1.0351.703) in Group 2. After coadministration of edoxaban and prasugrel for 5 days, BT was further prolonged. Especially in the edoxaban plus $3.75 \mathrm{mg}$ prasugrel group, bleeding was continued over $10 \mathrm{~min}$ in 5 out of $12 \mathrm{sub}-$ jects. The GLSMs of BT ratios were 1.581 (90\% CI 1.197-2.087) in the edoxaban plus $2.5 \mathrm{mg}$ prasugrel group and 1.996 (90\% CI 1.482-2.690) in the edoxaban plus $3.75 \mathrm{mg}$ prasugrel group. The GLSM increases in BT by prasugrel (edoxaban plus prasugrel/edoxaban alone) were 1.442 (90\% CI 1.096-1.897) in the edoxaban plus $2.5 \mathrm{mg}$ prasugrel group and 1.504 (90\% CI $1.172-$ 1.930 ) in the edoxaban plus $3.75 \mathrm{mg}$ prasugrel group.

\section{Pharmacodynamic parameters of coagulation and platelet aggregation}

Figure 2 provides an overview of changes in pharmacodynamic parameters of coagulation and platelet

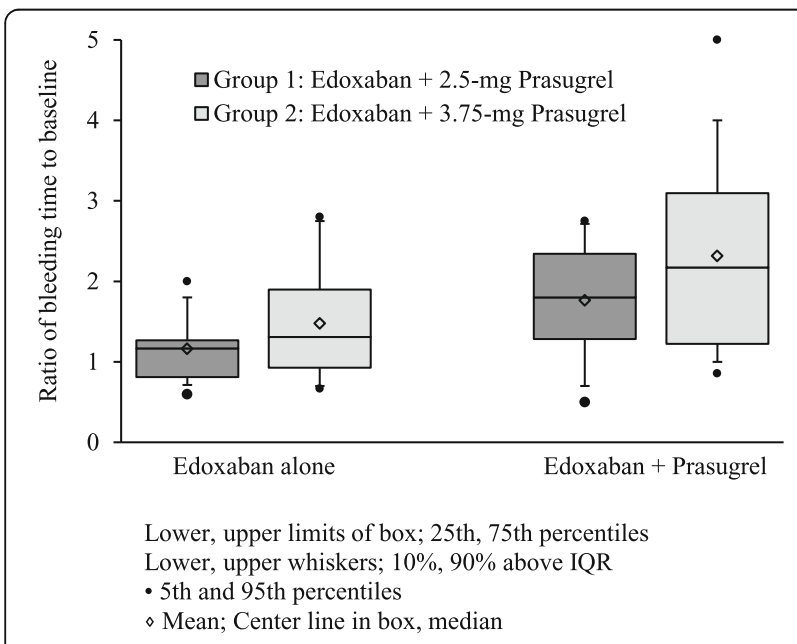

Fig. 1 Changes in bleeding time induced by edoxaban administered alone and with prasugrel aggregation. The administration of $30 \mathrm{mg}$ edoxaban prolonged PT, in sec, from a mean of 11.8 at baseline to 15.3 (Group 1) and 11.9 at baseline to 15.5 (Group 2). With the addition of $2.5 \mathrm{mg}$ or $3.75 \mathrm{mg}$ prasugrel, the PT values were essentially unchanged for both groups (mean of 15.2 and 15.1). The aPTT, in sec, was also prolonged by edoxaban, from 31.9 at baseline to 38.0 (Group 1) and 34.2 at baseline to 39.9 (Group 2). Again, when $2.5 \mathrm{mg}$ or $3.75 \mathrm{mg}$ prasugrel was added on to the administration, the effect of edoxaban on aPTT, in sec, was unchanged (mean of 37.7 and 39.1). Edoxaban decreased $\mathrm{F} 1+2$, in pmol/L, from 309 at baseline to 112 (Group 1) and 279 at baseline to 129 (Group 2). The results of $\mathrm{F} 1+2$, were essentially unchanged when $2.5 \mathrm{mg}$ or $3.75 \mathrm{mg}$ prasugrel was added on to the administration of edoxaban (mean of 123 and 120). In the platelet aggregation assay, edoxaban essentially had no effect on PRU. After $2.5 \mathrm{mg}$ or $3.75 \mathrm{mg}$ prasugrel was added on to edoxaban, the PRU was reduced from a mean of 249 at baseline to 158 and 246 at baseline to 78 , respectively.

\section{Pharmacokinetics}

The plasma edoxaban concentration profiles over $24 \mathrm{~h}$ were consistent, whether edoxaban was administered alone or with $2.5 \mathrm{mg}$ or $3.75 \mathrm{mg}$ prasugrel, as shown in Fig. 3. Also, prasugrel did not affect the PK parameters $\left(C_{\text {max,ss }}, A C_{\text {tau,ss }}, t_{\text {max,ss }}\right)$ of edoxaban (Table 4$)$.

\section{Safety}

Of the 24 participants, 16 had at least one occurrence of a treatment-emergent adverse event (AE) (16 positive results in the fecal occult blood test without stool blackening; 2, constipation). We observed 26 treatmentemergent AEs: 23 were reported as a treatment-related $\mathrm{AE}$ (positive result in the fecal occult blood test), and 3 were an AE unrelated to treatment (constipation) and most likely due to environmental changes at the hospital. We observed four positive results in the fecal occult blood test for edoxaban alone, 10 for edoxaban plus $2.5 \mathrm{mg}$ prasugrel, and 9 for edoxaban plus $3.75 \mathrm{mg}$ prasugrel and confirmed the recovery of all participants during the follow-up period. No serious adverse event was observed in the study. There were also no withdrawals or discontinuation of the study drug due to AEs or any other reason.

\section{Discussion}

This study provided additional, preliminary safety results that concur with the 2018 joint European consensus document [2] recommending dual-therapy use of a DOAC plus a $\mathrm{P}_{2} \mathrm{Y}_{12}$ receptor inhibitor and also found no effect of prasugrel on PK and PD of edoxaban in healthy Japanese 
(A)

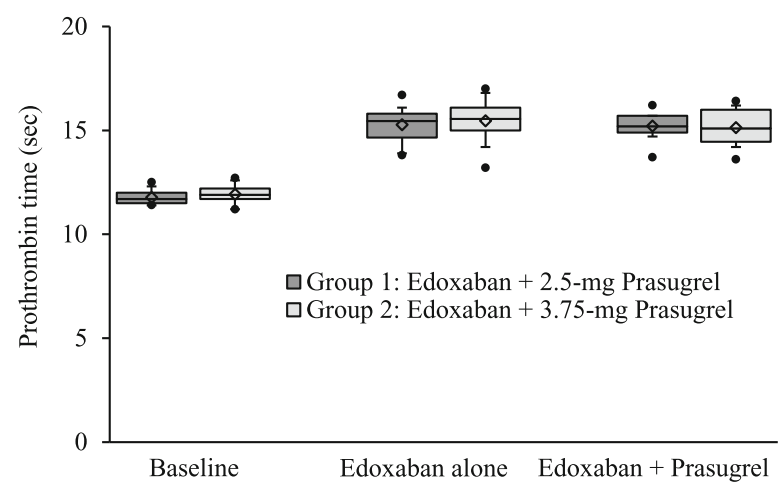

(C)

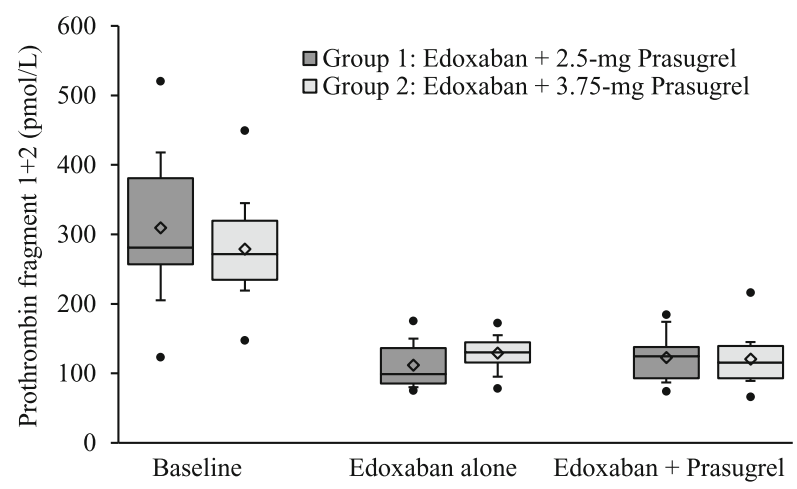

Lower, upper limits of box; 25 th, 75 th percentiles

- 5th and 95th percentiles
(B)

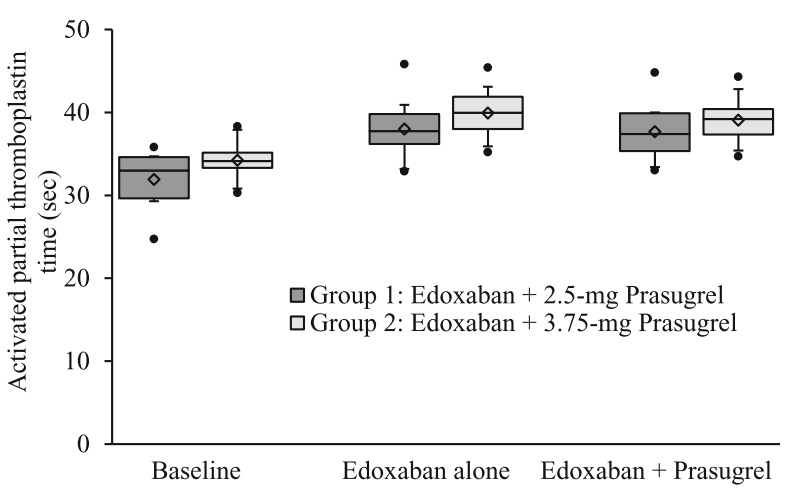

(D)

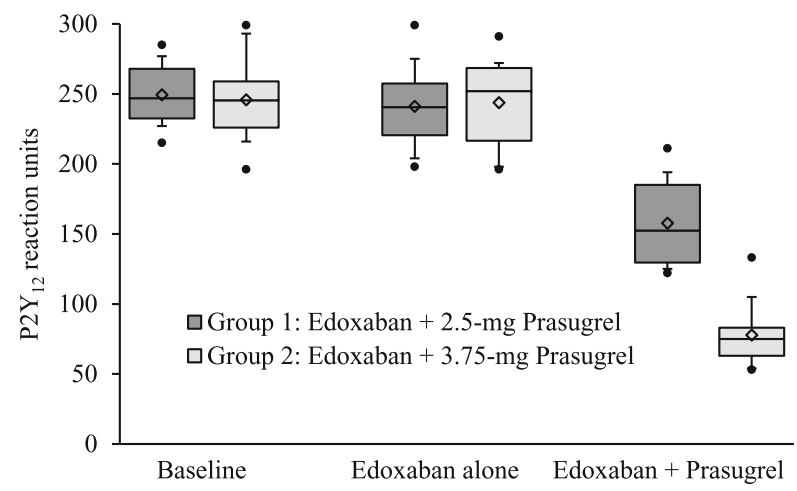

Lower, upper whiskers; $10 \%, 90 \%$ above IQR

- Mean; Center line in box, median

Fig. 2 Changes in pharmacodynamic indices of coagulation and platelet aggregation induced by edoxaban administered alone and with prasugrel (a) Prothrombin time; (b) Activated partial thromboplastin time; (c) Prothrombin fragment 1+2; (d) P2Y 12 reaction units

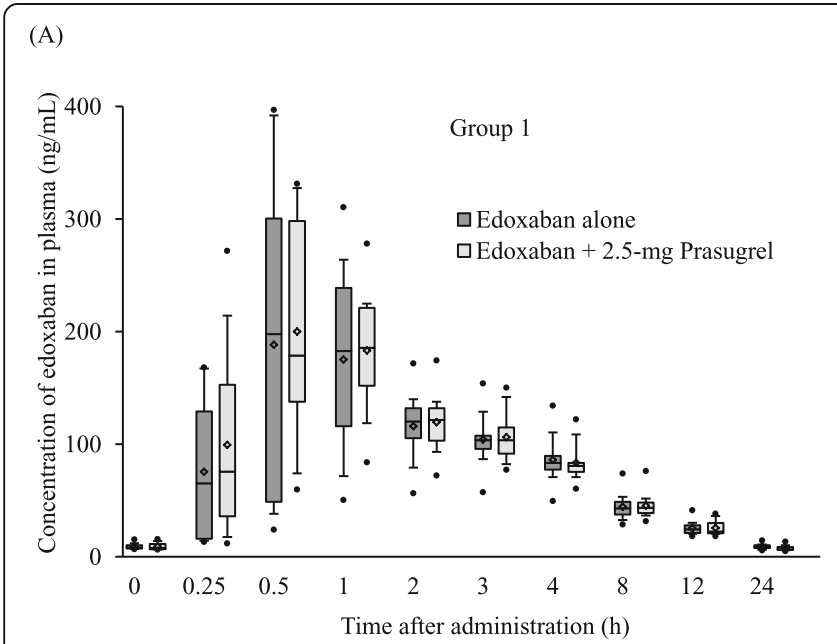

Lower, upper limits of box; 25 th, 75 th percentiles

- 5th and 95th percentiles
(B)

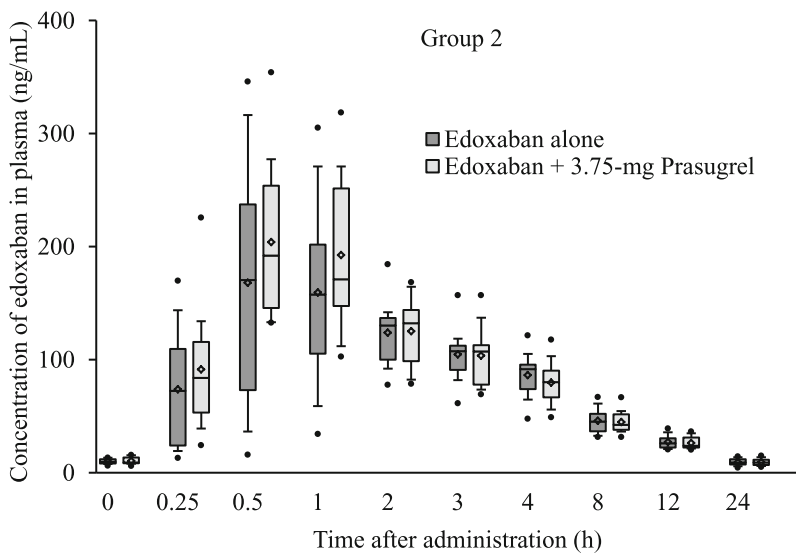

Lower, upper whiskers; $10 \%, 90 \%$ above IQR

- Mean; Center line in box, median

Fig. 3 Effect of prasugrel on edoxaban concentrations in plasma (a) Group 1, administration of 30 mg edoxaban alone compared with 30 mg edoxaban plus $2.5 \mathrm{mg}$ prasugrel; (b) Group 2, administration of $30 \mathrm{mg}$ edoxaban alone compared with 30 mg edoxaban plus $3.75 \mathrm{mg}$ prasugrel 
Table 4 Pharmacokinetic parameters of edoxaban

\begin{tabular}{|c|c|c|c|c|}
\hline & \multicolumn{2}{|l|}{$\begin{array}{l}\text { Group } 1 \\
30 \mathrm{mg} \text { edoxaban plus } \\
2.5 \mathrm{mg} \text { prasugrel }\end{array}$} & \multicolumn{2}{|l|}{$\begin{array}{l}\text { Group } 2 \\
30 \mathrm{mg} \text { edoxaban plus } \\
3.75 \mathrm{mg} \text { prasugrel }\end{array}$} \\
\hline & \multicolumn{2}{|l|}{$n=12$} & \multicolumn{2}{|l|}{$n=12$} \\
\hline & Edoxaban alone & $\begin{array}{l}\text { Edoxaban plus } \\
\text { prasugrel }\end{array}$ & Edoxaban alone & $\begin{array}{l}\text { Edoxaban plus } \\
\text { prasugrel }\end{array}$ \\
\hline \multicolumn{5}{|l|}{$C_{\text {max }, \text { ss }}(\mathrm{ng} / \mathrm{mL})$} \\
\hline Mean (SD) & $216.0(112.4)$ & $216.0(80.4)$ & $191.4(79.7)$ & $216.9(68.1)$ \\
\hline Median (IQR) & $199.8(127.6-300.5)$ & 187.8 (169.0-298.3) & $170.5(134.5-237.3)$ & $216.6(157.3-269.3)$ \\
\hline \multicolumn{5}{|c|}{$A \cup C_{\text {tau,ss }}(\mathrm{ng} \mathrm{h} / \mathrm{mL})$} \\
\hline Mean (SD) & $1059.4(228.0)$ & $1068.6(189.8)$ & $1070.4(239.7)$ & $1088.5(223.2)$ \\
\hline Median (IQR) & $1025.0(924.2-1152.4)$ & $1005.8(912.2-1216.7)$ & 992.5 (953.1-1206.7) & $1049.6(930.4-1240.1)$ \\
\hline \multicolumn{5}{|l|}{$t_{\text {max }, s s}(h)$} \\
\hline Mean (SD) & $1.2(0.96)$ & $0.92(0.70)$ & $1.0(0.84)$ & $0.71(0.26)$ \\
\hline Median (IQR) & $0.75(0.50-1.5)$ & $0.75(0.50-1.0)$ & $0.50(0.50-1.5)$ & $0.50(0.50-1.0)$ \\
\hline
\end{tabular}

$C_{\text {max }, s s}$ steady state maximum plasma concentration, $A \cup C_{\text {tau,ss }}$ steady state area under the plasma concentration-time curve, $t_{\text {max ss }}$ steady state time to reach maximum plasma concentration, $S D$ standard deviation, $I Q R$ interquartile range

male subjects of normal weight (50 to $60 \mathrm{~kg}$; BMI $21.1 \pm$ $\left.1.6 \mathrm{~kg} / \mathrm{m}^{2}\right)$ and advanced age (65 to 80 years).

Results of BT measured by the Ivy method were predictable and confirmatory for coadministration of edoxaban with prasugrel. Edoxaban $(30 \mathrm{mg}$ ) alone prolonged BT 1.10- or 1.33-fold from baseline, and the addition of $2.5 \mathrm{mg}$ and $3.75 \mathrm{mg}$ prasugrel to edoxaban further prolonged BT 1.58- or 2.00-fold, respectively. The effect of prasugrel on BT was dose-dependent. This two-fold increase was comparable to the coadministration of $60 \mathrm{mg}$ edoxaban with aspirin or naproxen, antiplatelet agents used in the study of Mendell et al. [13] and less than a 3.8-fold increase after the coadministration of $15 \mathrm{mg}$ rivaroxaban with standard doses of clopidogrel [14]. The incidence of bleeding events caused by the concomitant treatment with $60 \mathrm{mg}$ edoxaban plus aspirin has been evaluated in patients with peripheral artery disease who have undergone endovascular treatment [15]. The bleeding risk of $60 \mathrm{mg}$ edoxaban plus aspirin was similar to that of standard dual antiplatelet therapy with clopidogrel plus aspirin [15]. Another clinical study showed that concomitant use of $15 \mathrm{mg}$ rivaroxaban with clopidogrel in NVAF patients undergoing PCI was associated with a lower rate of clinically significant bleeding when compared to standard therapy with a vitamin $\mathrm{K}$ antagonist plus dual antiplatelet therapy [16]. Although BT may not always be correlated with bleeding risk in patients receiving antithrombotic agents $[17,18]$, the present data suggest that bleeding risk by dual-therapy edoxaban and prasugrel might be low.

The results of PD and PK parameters were also predictable and confirmatory. As expected, edoxaban alone prolonged PT and aPTT and decreased $\mathrm{F} 1+2$.
Combined treatment with prasugrel had no additional effect on these parameters. In terms of platelet function, edoxaban alone had no effect on platelet aggregation, and only after administration of prasugrel, platelet aggregation was suppressed. Coadministration of prasugrel with edoxaban did not affect the PK parameters of edoxaban. These results of the combined administration of DOAC edoxaban and $\mathrm{P}_{2} \mathrm{Y}_{12}$ receptor inhibitor prasugrel are consistent with those reported previously for rivaroxaban and clopidogrel [14]; clopidogrel did not alter the anticoagulant effects and PK of rivaroxaban, whereas platelet aggregation was not affected by rivaroxaban.

This study reports safety results on the coadministration of edoxaban with prasugrel in a small study. All the treatment-emergent AEs were non-serious AEs. Most of the AEs were a positive fecal occult blood test, and all subjects with this AE did not require any treatment during the study period. Additionally, no study withdrawal or discontinuation due to AEs were observed.

It is also important to note that the reduced dose of edoxaban $(30 \mathrm{mg}$ ) is used in $82 \%$ of elderly ( $\geq 75$ years of age) AF patients in Japan [1]. Thus, for elderly AF patients undergoing PCI, clinicians can consider giving the reduced $30 \mathrm{mg}$ dose of edoxaban with either the $2.5 \mathrm{mg}$ or $3.75 \mathrm{mg}$ dose of prasugrel. Since the effect of prasugrel on BT was dose-dependent, $2.5 \mathrm{mg}$ prasugrel would be an option for patients whose body weight is $\leq 50 \mathrm{~kg}$ or who have other risk factors for bleeding.

There are several limitations of the study. First, this is a small clinical pharmacology study of short-term treatment in healthy elderly Japanese male subjects. Although we have set the duration of treatment for the purpose of reaching the steady states of $\mathrm{PK}$ variables for both 
edoxaban and prasugrel, according to the European consensus document [2] up to 12 months of treatment of dual therapy with an oral anticoagulant plus a $\mathrm{P}_{2} \mathrm{Y}_{12}$ receptor inhibitor are required for AF patients undergoing PCI. Large clinical studies are required to assess the concomitant use of edoxaban and prasugrel over a longer period in these patients, especially in patients who are at high-risk for bleeding. Second, it would be hard to predict bleeding risk of antithrombotic agents by BT results only $[17,18]$. However, BT is currently the only method used to assess the risk of bleeding in clinical pharmacological studies of antithrombotic agents or combined effects of anticoagulant and antiplatelet agents [13, 14]. The increase in BT in a clinical study may indicate a potential for a higher risk of bleeding.

\section{Conclusions}

Coadministration of the $\mathrm{P}_{2} \mathrm{Y}_{12}$ receptor inhibitor $2.5 \mathrm{mg}$ and $3.75 \mathrm{mg}$ prasugrel with the DOAC $30 \mathrm{mg}$ edoxaban prolonged BT in healthy elderly Japanese male subjects. The BT prolongation was dependent on the dose of prasugrel. Prasugrel did not affect PD or PK parameters of edoxaban.

\section{Abbreviations}

AE: Adverse event; aPTT: Activated partial thromboplastin time; BT: Bleeding time; Cl: Confidence interval; DOAC: Direct oral anticoagulant; eGFR: Estimated glomerular filtration rate; F1 + 2: Prothrombin fragment $1+$ 2; GLSM: Geometric least squares mean; NVAF: Nonvalvular atrial fibrillation; PCl: Percutaneous coronary intervention; PD: Pharmacodynamic; PK: Pharmacokinetic; PRU: P2Y $_{12}$ reaction units; PT: Prothrombin time; SAS: Safety analysis set

\section{Acknowledgments}

The authors wish to acknowledge Keita Yamaguchi (Daiichi Sankyo Co., Ltd.) and Hideyuki Tomitori (IQVIA Services Japan K.K., Tokyo, Japan) for coordinating the research activity and assisting with the drafting of the manuscript. Additionally, the authors are indebted to Takahiro Horii (IDD Inc. Tokyo, Japan), Kazuhiro Kanmuri (Inter-Professional Inc., Tokyo, Japan) and Mary Y. Nishikawa (Yokohama, Japan) for their medical writing and editorial support.

\section{Authors' contributions}

II established the study concept and design, conducted the research process, acquired, and interpreted the data, and reviewed the manuscript. TA and TM established the study concept and design, interpreted the data, and reviewed the manuscript. YM established the study concept and design, managed, and coordinated research activities, interpreted the data, and contributed to the drafting of the manuscript. AT designed the statistical analyses, interpreted the data, and reviewed the manuscript. TK established the study concept and design, managed, coordinated the research activity, interpreted the data, and reviewed the manuscript. All authors read and approved the final manuscript.

\section{Funding}

This study and medical writing services were sponsored by Daiichi Sankyo Co., Ltd.

\section{Availability of data and materials}

The corresponding author can make available a minimal dataset upon reasonable request.

\section{Ethics approval and consent to participate}

The study was conducted in compliance with the ethical principles of the Declaration of Helsinki and International Conference on Harmonization Guidelines for Good Clinical Practice. The Kyushu University Certified Institutional Review Board for Clinical Trials reviewed the study protocol and informed consent documents following the 2018 Clinical Research Act of Japan. The Certified Institutional Review Board for Clinical Trials found the study in compliance with clinical research methods and protocols described therein and approved the study. The study was registered in the Japan Registry of Clinical Trials No. jRCTs071190006 on April 26, 2019.

All participants were required to provide direct, written consent for participation in the study.

\section{Consent for publication}

Not applicable.

\section{Competing interests}

This study was supported by Daiichi Sankyo Co., Ltd. Daiichi Sankyo was involved in the design of the study and drafting of the manuscript. IDD Inc. (Tokyo, Japan) oversaw the monitoring, data management, statistical analysis, and other duties. The audit was conducted by CMIC HOLDINGS Co., Ltd. (Tokyo, Japan).

II declares that he has no other competing interests. TA, YM, AT, TM, and TK are employees of Daiichi Sankyo Co., Ltd.

\section{Author details}

${ }^{1}$ Sumida Hospital, 29-1, Honjo 1-Chome, Sumida-ku, Tokyo 130-0004, Japan. ${ }^{2}$ Medical Science Department, Daiichi Sankyo Co., Ltd., 3-5-1 Nihonbashi Honcho, Chuo-ku, Tokyo 103-8426, Japan. ${ }^{3}$ Biostatistics \& Data Management Department, Daiichi Sankyo Co., Ltd., 1-2-58 Hiromachi, Shinagawa-ku, Tokyo 140-8710, Japan.

Received: 26 November 2019 Accepted: 19 May 2020

Published online: 12 June 2020

\section{References}

1. Koretsune $Y$, Yamashita T, Akao M, Atarashi H, Ikeda T, Okumura K, et al. Baseline demographics and clinical characteristics in the all Nippon AF in the elderly (ANAFIE) registry. Circ J. 2019;83(7):1538-45.

2. Lip GYH, Collet J-P, Haude M, Byrne R, Chung EH, Fauchier L, et al. 2018 Joint European consensus document on the management of antithrombotic therapy in atrial fibrillation patients presenting with acute coronary syndrome and/or undergoing percutaneous cardiovascular interventions: a joint consensus document of the EuropeanHeart Rhythm Association (EHRA), European Society of Cardiology Working Group on Thrombosis, European Association of Percutaneous Cardiovascular Interventions (EAPCI), and European Association of Acute Cardiac Care (ACCA) endorsed by the Heart Rhythm Society (HRS), Asia-Pacific Heart Rhythm Society (APHRS), Latin America Heart Rhythm Society (LAHRS), and Cardiac Arrhythmia Society of Southern Africa (CASSA). Europace. 2019;21(2): 192-3.

3. Furugohri T, Isobe K, Honda Y, Kamisato-Matsumoto C, Sugiyama N, Nagahara T, et al. DU-176b, a potent and orally active factor Xa inhibitor: in vitro and in vivo pharmacological profiles. J Thromb Haemost. 2008;6(9): 1542-9.

4. Giugliano RP, Ruff CT, Braunwald E, Murphy SA, Wiviott SD, Halperin JL, et al Edoxaban versus warfarin in patients with atrial fibrillation. N Engl J Med. 2013;369(22):2093-104

5. Bounameaux H, Camm AJ. Edoxaban: an update on the new oral direct factor Xa inhibitor. Drugs. 2014;74(11):1209-31.

6. Sugidachi A, Asai F, Ogawa T, Inoue T, Koike H. The in vivo pharmacological profile of CS-747, a novel antiplatelet agent with platelet ADP receptor antagonist properties. Br J Pharmacol. 2000;129(7):1439-46.

7. Wiviott SD, Braunwald E, McCabe CH, Montalescot G, Ruzyllo W, Gottlieb S, et al. Prasugrel versus Clopidogrel in patients with acute coronary syndromes. N Engl J Med. 2007;357(20):2001-15.

8. Saito S, Isshiki T, Kimura T, Ogawa H, Yokoi H, Nanto S, et al. Efficacy and safety of adjusted-dose Prasugrel compared with Clopidogrel in Japanese patients with acute coronary syndrome. Circ J. 2014;78(7):1684-92.

9. Isshiki T, Kimura T, Ogawa H, Yokoi H, Nanto S, Takayama M, et al. Prasugrel, a third-generation $\mathrm{P}_{2} \mathrm{Y}_{12}$ receptor antagonist, in patients with coronary 
artery disease undergoing elective percutaneous coronary intervention. Circ J. 2014;78(12):2926-34.

10. Otsuki H, Yamaguchi J, Kawamoto T, Yoshikawa M, Ebihara S, Tanaka K, et al. Safety and efficacy of low-dose prasugrel as part of triple therapy with aspirin and Oral anticoagulants in patients with atrial fibrillation undergoing percutaneous coronary intervention - from the TWMU-AF PCI registry - . Circ J. 2019;83(5):1000-5.

11. Vranckx P, Valgimigli M, Eckardt L, Tijssen J, Lewalter T, Gargiulo G, et al. Edoxaban-based versus vitamin $\mathrm{K}$ antagonist-based antithrombotic regimen after successful coronary stenting in patients with atrial fibrillation (ENTRUST-AF PCI): a randomised, open-label, phase 3b trial. Lancet. 2019; 394(10206):1335-43.

12. Mielke CH, Kaneshuro MM, Maher IA, Weiner JM, Rapaport SI. The standardized Normal ivy bleeding time and its prolongation by aspirin. Blood. 1969;34(2):204-15.

13. Mendell J, Lee F, Chen S, Worland V, Shi M, Samama MM. The effects of the antiplatelet agents, aspirin and naproxen, on pharmacokinetics and pharmacodynamics of the anticoagulant edoxaban, a direct factor Xa inhibitor. J Cardiovasc Pharmacol. 2013;62(2):212-21.

14. Kubitza D, Becka M, Mück W, Schwers S. Effect of co-administration of rivaroxaban and clopidogrel on bleeding time, pharmacodynamics and pharmacokinetics: a phase I study. Pharmaceuticals. 2012;5(3):279-96.

15. Moll F, Baumgartner I, Jaff M, Nwachuku C, Tangelder M, Ansel G, et al. Edoxaban plus aspirin vs dual antiplatelet therapy in endovascular treatment of patients with peripheral artery disease: results of the ePAD trial. J Endovasc Ther. 2018;25(2):158-68.

16. Gibson CM, Mehran R, Bode C, Halperin J, Verheugt FW, Wildgoose P, et al. Prevention of bleeding in patients with atrial fibrillation undergoing PCI. N Engl J Med. 2016;375(25):2423-34.

17. De Caterina R, Lanza M, Manca G, Strata G, Maffei S, Salvatore L. Bleeding time and bleeding: an analysis of the relationship of the bleeding time test with parameters of surgical bleeding. Blood. 1994;84(10):3363-70.

18. Barber A, Green D, Galluzzo T, Ts'ao CH. The bleeding time as a preoperative screening test. Am J Med. 1985;78(5):761-4.

\section{Publisher's Note}

Springer Nature remains neutral with regard to jurisdictional claims in published maps and institutional affiliations.

Ready to submit your research? Choose BMC and benefit from:

- fast, convenient online submission

- thorough peer review by experienced researchers in your field

- rapid publication on acceptance

- support for research data, including large and complex data types

- gold Open Access which fosters wider collaboration and increased citations

- maximum visibility for your research: over $100 \mathrm{M}$ website views per year

At $\mathrm{BMC}$, research is always in progress.

Learn more biomedcentral.com/submissions 